\title{
A Teoria das Restrições como Balizadora das Ações Visando a Troca Rápida de Ferramentas
}

José Antônio Valle Antunes Jr.

Mestre em Engenharia de Produção pela UFSC. Professor do mestrado em Engenharia de Produção da UFRGS.

\section{Luís Henrique Rodrigues}

Doutorando do Department of Operational Research da Universidade de Lancaster (Inglaterra).

\section{Escola de Engenharia da UFRGS}

Programa de Pós-Graduação em Engenharia de Produção

Prédio antigo - Sala 406

Pça Argentina s/no

CEP 90040-020 - Porto Alegre - RS

Palavras chave: Gerência de Produção, TDC, Troca Rápida de Ferramentas

Key words: Operations Management, TOC, System SMED

\section{RESUMO}

O presente artigo propõe a sinergia entre duas técnicas famosas no contexto da gestão industrial: a Troca Rápida de Ferramenta (TRF) e a Teoria das Restrições (Theory of Constraints TOC).

Para tanto, inicialmente, discute-se a problemática macroeconômica e sua vinculação com o aspecto microeconômico da TRF. Posteriormente, discute-se as principais vantagens potenciais decorrentes da redução dos custos e dos tempos de preparação. Na seqüência, revisa-se o método da TRF, pontuando-se que a abordagem apresenta uma deficiência no que concerne à apresentação de um procedimento de priorização que permita um plano lógico de ataque à questão. Neste ponto do texto, propõe-se a TOC como balizadora das ações visando a Troca Rápida de Ferramentas. Após uma breve revisão teórica da TOC, apresenta-se uma discussão sobre a possível sinergia da mesma com a TRF. Finalmente, apresenta-se um exemplo didático e as conclusões finais do artigo.

\section{ABSTRACT}

This paper presents the relationship between two well-known techniques within Industrial Management: SMED and the Theory of Constraints (TOC). As a first step, it is discussed the macroeconomics environment and its relationship with microeconomics aspects of the SMED. After that, the main advantages of cost and set-up time reductions are discussed and the TOC is proposed as a way to define priorities to SMED activities. Both, SMED concepts and TOC concepts are presented in this paper. Finally, an example is built up to show the synergy between the two techniques and a conclusion is presented. 


\section{A Problemática Econômica e sua Vinculação com a Troca Rápida de Ferramentas}

Este texto insere-se no contexto do ajustamento do sistema econômico internacional ocorrido a partir dos anos 70 - processo que afetou, de maneira radical, os padrões da competitividade internacional em geral, e os padrões da competitividade industrial em particular. Neste contexto, torna-se cada vez mais necessária a redefinição da estratégia das empresas como um todo e a criação, adaptação e ajuste de sistemas e técnicas de produção de forma compatível com as novas normas de concorrência.

\section{A lógica macroeconômica}

A economia capitalista mundial sofreu fortes modificações a partir dos anos 70. Segundo Coriat (1988), nos grandes setores de produção em massa de produtos discretos (automóveis, eletrodomésticos, etc.) e nos produtos intermediários (siderurgia, petroquímica, etc.) as capacidades instaladas de produção eram inferiores à demanda global do mercado. A crise vivenciada pela economia mundial nos anos 70 reverte esta situação. Em outras palavras, com a recessão dos anos 70 as capacidades instaladas nestes setores dinâmicos de economia tornaram-se superiores à demanda total de produtos requeridos pelos consumidores. Em função disto, passa a haver uma situação de concorrência acirrada a nível de muitos complexos oligopolísticos internacionais.

Desta forma, a crise do petróleo que ocorreu em 1973 alterou enormemente o cenário econômico de todo o mundo. Do ponto de vista comercial, o período anterior de 1973 pode ser considerado como "PRODUCTOUT", onde os fabricantes definiam e ofereciam os produtos a serem consumidos. A partir de então, entra-se na lógica do "MARKET-IN" onde o próprio mercado passa a definir suas exigências (Yamashina, 1988).

Do ponto de vista do surgimento de novas lógicas produtivas, este período histórico é bastante rico, dado que a concorrência intercapitalista acirra-se. Isto ocorre porque ela assenta-se na concorrência intercapitalista no próprio processo de produção.

As consequências práticas a nível da demanda de mercado derivadas da crise dos anos 70 podem ser sucintamente descritas da seguinte forma:

a) ocorre "um ligeiro incremento nas vendas (globais) em relação ao passado"; (Yamashina, 1988);

b) para as empresas tornarem-se competitivas no mercado precisam produzir lotes cada vez menores de artigos diferenciados. Em todos os casos a manutenção da competitividade neste tipo de lógica mercadológica exige que as empresas garantam, simultaneamente, para uma gama bastante diversificada de produtos, preços compativeis, qualidade intrínseca (que envolve todo o ciclo de venda do produto incluindo os serviços de pós-entrega) e atendimento aos prazos de entrega.

Este processo histórico da competição está na base do desenvolvimento e, principalmente, da rápida difusão por parte dos japoneses, dos sistemas do tipo JIT/TQC e das principais técnicas de sustentação dos mesmos, como é o caso da Troca Rápida de Ferramentas. 


\section{Influência da escala de complexidade da produção nos custos industriais}

Uma abordagem que permite vincular a análise feita no item anterior no campo "macro" com a ótica micro-econômica do Lote Econômico da Fabricação é exposta no artigo "Time the next source of competitive advantage" (Stalk, 1988).

Segundo uma das tipologias possiveis, os custos de produção podem provir de duas fontes básicas gerais: aquelas que se relacionam diretamente com o volume ou escala de produção e as que são dirigidas pela lógica da diversificação dos produtos fabricados. Para as fábricas que operam de acordo com as formas de produção tradicional (JIC) amplamente hegemônicas até a crise dos anos 70 , pode-se dizer empiricamente que ocorre uma redução de 15 a $20 \%$ do custo unitário do produto cada vez que o volume total de produção é duplicado. Este é um modo direto da escala de produção. Quanto aos custos relacionados à diversificação, pode-se dizer que eles estão diretamente vinculados a complexidade da estrutura produtiva em virtude de fatores, tais como: movimentação de materiais, controle de qualidade, inventários, troca de ferramentas, etc. Para um conjunto grande de situações práticas, pode-se afirmar, empiricamente, que ocorre um acréscimo de 20 a $25 \%$ do custo unitário cada vez que a diversificação dos produtos é duplicada (por exemplo, passando de 50 a 100 artigos diferentes).

A mudança das normas de concorrência ocorrida nos anos 70 estabelece um impasse: há uma clara inviabilidade de se aumentar a diversificação dos produtos necessários pela pressão do mercado, associando a isto uma redução de custos, mantendo uma organização da produção e do trabalho segundo a concepção tradicional ("Just-in-Case") nas fábricas.

A introdução processual do sistema justin-time vem no bojo e como alternativa a este processo tradicional. Mas, como sucintamente coloca Shingo (1983), o "JIT é um fim, mas não um meio". Ou seja, "sem compreender as técnicas e métodos práticos que formam o coração do JIT, não há sentido no sistema JIT por si só. "É exatamente neste ponto que algumas barreiras e crenças culturais serão rompidas e conceitos tradicionais, como o lote econômico de fabricação, sofrerão fortes questionamentos.

\section{A lógica micro-econômica -a questão do lote econômico de fabricação}

A primeira questão que surge refere-se à seguinte indagação: é econômico estocar o item entre duas unidades de fabricação? (Dias, 1988) - De forma geral, nunca é econômico estocar um item se isto excede o custo de comprá-lo ou produzí-lo, de acordo com as necessidades. ${ }^{(1)}$

Porém, uma vez decidido pela necessidade de estocar um certo item ou componente genérico, uma outra pergunta torna-se imediatamente essencial: quanto deve ser comprado ou produzido de cada vez? Diversas situações podem ocorrer na prática, sendo que a seguir apresentar-se-á uma dedução sucinta do chamado lote econômico de fabricação.

\footnotetext{
(1) De forma global pode-se falar em lote econômico. O lote econômico pode ser de compra, de fabricação ou de venda. Para efeito do trabalho sobre Troca Rápida de Ferramenta é importante a noção de Lote Econômico de Fabricação.
} 


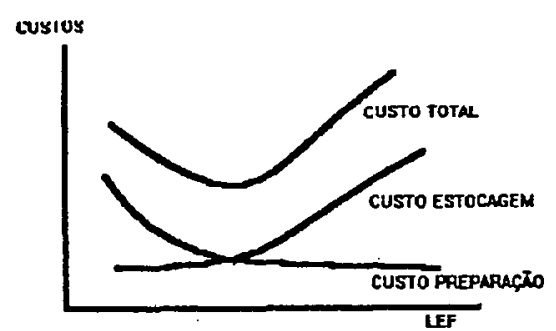

Figura 1 - As hipóteses centrais para a definição do lote econômico de fabricação sem faltas são as seguintes:

- o consumo mensal é determinístico e com uma taxa constante;

- a produção é retomada instantaneamente quando os estoques chegam a zero;

- a quantidade a ser produzida é finita e necessariamente maior do que o consumo.

Após trabalhar-se visando minimizar o somatório do custo de estocagem e o de preparação - Custo Total, obtêm-se:

$$
Q_{e}=\sqrt{\frac{2 A C}{i *(1-c / w)}}
$$

onde:

$Q_{\text {e }}=$ lote econômico de fabricação para o mínimo custo.

$A=$ custo de armazenagem unitário (custo de programação, preparação do lote de produção propriamente dito, deslocamento das matérias-primas até as máquinas, etc.)

$\mathrm{i}=$ custo de armazenagem unitário (proveniente do custo do capital, custo dos seguros, custo dos armazéns, etc.)

$c=$ consumo (unidades/tempo)

$w=$ taxa de produção (unidades/tempo)

Da fórmula acima, uma importante observação deve ser explicitada. Note-se que $Q_{e} \approx \sqrt{A}$, ou seja, o lote econômico de fabricação é proporcional à raiz quadrada do custo de preparação.

Até o início dos anos 70 não havia um amplo questionamento visando a redução dos custos de preparação das máquinas, o que resultava na necessidade da produção de grandes lotes de fabricação. Esta questão é claramente explicitada por Sayer (1986).

\section{Troca rápida de ferramentas - uma necessidade operacional a nível do chão de fábrica.}

A partir da discussão feita nos itens anteriores, torna-se claro que as normas de concorrência intercapitalista alteraram-se profundamente nos anos 70. Até então muitos setores industriais (por exemplo, automóveis) caracterizavam-se pela produção em massa, associando a isto a produção de grandes lotes de fabricação. Porém, é preciso deixar claro que com a modificação das condições de concorrência de mercado, começou-se a dissociar a produção em massa de grandes lotes de produção, percebendo-se que tratam-se de questões diferentes. Surge, assim, um impasse em toda a produção fabril, iniciando-se um processo de investigação de soluções práticas para esta questão.

Entre as soluções possíveis, desenvolveuse o chamado "Sistema Toyota de Produção" no qual a troca rápida de ferramentas é uma das técnicas operacionais centrais, dado que vai ajudar diretamente no sentido de reduzir significativamente o custo de preparação das máquinas. Assim, pode-se situar a TRF como uma necessidade subordinada à alteração das normas concorrenciais no campo macroeconômico.

Finalmente, é preciso observar que o sistema de troca rápida de ferramentas em particular e o "Sistema Toyota de Produção" em geral, não se constituem em "uma anti-tese contra a produção em massa, mais sim em 
uma anti-tese contra a produção de grandes lotes" (Shingo, 1981).

\section{Principais Vantagens Decorrentes da}

\section{Redução dos Custos e}

dos Tempos de

\section{Preparação das}

Máquinas

Segundo uma das tipologias possiveis, existem basicamente 4 vantagens principais associadas à redução dos custos de preparação:

1) A redução do custo de preparação permite que as fábricas respondam mais rapidamente às variáveis da demanda do mercado, dado que é possivel trabalhar-se com lotes cada vez menores. Ainda de acordo com Yamashina, (1988) pode-se dizer que a lógica da troca rápida de ferramentas permite uma maior "flexibilidade para introduzir modificações e alterações no planejamento do produto". Isto ocorre porque, com tempos de preparação reduzidos, há possibilidade de reduzirse os tempos de passagem ou de atravessamento (lead-time).

2) A possibilidade de trabalhar economicamente com lotes menores implica em reduzir radicalmente os inventários existentes na fábrica. A redução dos inventários implica nas seguintes conseqüências positivas:

- redução dos custos financeiros com consequente aumento do capital de giro;
- redução dos refugos e retrabalhos, visto que os defeitos são localizados em tempo mais curto e a fonte dos mesmos é mais facilmente detectável (Antunes, 1990);

- melhor uso do espaço disponível ou, em outras palavras, gera-se espaço físico para a expansão da produção sem a necessidade de investimentos;

- redução da perda de material por deterioração em estoques;

- redução do tempo de atravessamento ("lead-time");

- redução dos transportes de material;

- redução do número de itens a serem controlados nos vários instantes de tempo (Yamashina, 1987).

3) Com a utilização de técnicas cada vez mais simples e rápidas de troca de ferramentas minimiza-se as possibilidades de "erros na regulagem de ferramentas e instrumentos" (Harmon \& Petersen, 1991). Dentro deste contexto, existem técnicas de troca rápida de ferramentas criadas com o objetivo de minimizar as necessidades de ajuste, tais como: normalização funcional com auxilio de posicionadores e blocos, espassadores, etc. (Yamashina, 1988); a existência destas técnicas minimiza os custos da má qualidade, associados a erros de regulagem e ajustes.

4) Segundo Harmon \& Petersen (1991): "técnicas de conversão rápidas podem ser usadas para tornar disponivel uma capacidade adicional da máquina".(2)

\footnotetext{
(2) Cabe salientar que a afirmação de Petersen e Hamon, dentro da lógica da Teoria das Restrições está diretamente relacionada com a visão de ótimos locais. Em termos do ótimo global, esta afirmición somente é válida para os gargalos produtivos.
} 
Um bom exemplo desta situação, que relaciona-se historicamente com o surgimento do sistema de troca rápida de ferramentas, é dado por Shingo (1983).

No ano de 1950, Shingo foi contratado pela fábrica Toyo Kyyo's Malda, em Hiroshima, que produzia veículos de três rodas com o objetivo de eliminar os gargalos diretamente ligados a grandes prensas de 350,750 e 800 toneladas utilizadas na estampagem de painéis de carro. Estas máquinas, por constituírem-se em gargalos da produção, estavam trabalhando no limite máximo de suas "capacidades" técnicas de produção. Como a lógica tradicional "Just-in-Case" era amplamente hegemônica na época, a idéia vigente na fábrica era de que a expansão da produção dependeria de uma única saída possível: a compra de novos equipamentos para expandir a capacidade do gargalo.

Porém, Shingo buscou uma alternativa diretamente relacionada à troca de ferramenta nas prensas. Observando diretamente a troca de ferramenta na prensa de 800 toneladas, verificou que em um dado momento os operários começaram a correr na estamparia atrás de um parafuso de montagem da nova ferramenta que estava faltando. Isto permitiu a Shingo um "insight" essencial: as preparações podem ser de duas naturezas distintas: ou são feitas internamente, (on line) o que obriga a parada da máquina para a execução do trabalho, ou externamente (off line), ou seja, podem ser feitos paralelamente, enquanto a máquina está processando as peças. Obviamente, preparar parafuso é uma preparação externa. Através de um mero procedimento de preparação externa para a troca de ferramentas nas prensas, fazendo com que os elementos de fixação estivessem em condições para a próxima preparação, associado a uma opção correta do processo de escolha dos parafusos e colocação em caixas, houve um aumento de eficiência de $50 \%$ da máquina e este gargalo de produção foi eliminado.

Obviamente, todo o sistema de troca rápida de ferramentas desenvolvido originalmente por Shingo e, posteriormente, por outras pessoas, consultorias e grupos, são capazes de atacar amplamente esta questão.

Esta lógica quantitativa global foi explicitada teoricamente nos anos 80, de forma clara, por Goldratt (1986) através da máxima: "uma hora perdida no gargalo é uma hora perdida em todo o sistema". A metodologia de troca rápida de ferramentas é uma das técnicas essenciais para operacionalizar o conceito expresso por Goldratt. Cabe ressaltar, ainda, que entre os custos de depreciação da aquisição de um novo equipamento para atender o gargalo e o custo de uma solução associada ao desenvolvimento de uma técnica de conversão rápida de ferramentas, há sempre uma solução econômica que deve ser cuidadosamente analisada no presente e em uma perspectiva futura.

A seguir, desenvolver-se-á uma discussão específica desta última vantagem competitiva, visando abordar a problemática da troca rápida de ferramentas, desde um ponto de vista de sua priorização a nível dos gargalos produtivos. Em outras palavras, tratar-se-á das questões vinculadas às técnicas de conversão rápida visando um ganho de capacidade localizado no gargalo. O trabalho, neste momento, não abordará as demais vantagens potenciais provenientes da troca rápida de ferramentas. Para tanto, inicialmente abordar-se-á a metodologia geral para troca rápida de ferramentas expostas por Shingo e, posteriormente, a utilização da Teoria das Restrições como ferramenta de priorização de setups. 
Metodologia Geral para a Abordagem da Problemática da Troca Rápida de Ferramentas de Acordo com Shigeo Shingo

A seguir aborda-se os estágios conceituais propostos por Shigeo Shingo $(1983)^{(3)}$ visando atacar de forma genérica as questões associadas à troca rápida de ferramentas.

Estágio Preliminar - Preparação interna e externa não são distinguidas - Neste estágio as pessoas da organização não conseguem distinguir conceitualmente as noções de preparação interna (on line) das máquinas e preparação externa (off-line).

Estágio 1 - Separação da preparação interna da preparação externa - Segundo Shingo (1983) este é o mais importante passo no sentido da implantação do sistema de troca rápida de ferramentas.

Os mecanismos que podem ser utilizados nesse sentido, de acordo com Shingo (1983), são:

- uma análise contínua da produção feita através de cronometragem (STOPWATCH): provavelmente esta é a melhor abordagem; porém, requer muito tempo e grande qualificação por parte de quem executará a análise;

- uso do estudo do trabalho via amostragem: é um método adequado quando tem-se operações muito repetitivas; pode apresentar problemas quando as operações não forem repetitivas;

- estudo das condições reais de preparação: Shingo observa que o efeito do uso da fita é ótima solução; os operadores podem observar sua própria atuação imediatamente após a gravação; a oportunidade dos operadores se verem, muitas vezes os leva a soluções criativas e úteis para a melhoria dos set-ups.

Uma observação final do autor é bastante relevante. Shingo afirma que, embora alguns consultores advoguem teoricamente uma análise contínua da produção para o propósito de melhorar os set-ups, a verdade é "que observações informais e discussões com os trabalhadores é muitas vezes suficiente".

Ou seja, de forma ampla pode-se dizer que a distinção entre troca interna e externa é o passaporte para a obtenção da troca rápida de ferramentas.

Do ponto de vista prático, se tratarmos as operações de set-up o máximo possivel como externas, o tempo geralmente gasto para a preparação interna pode ser reduzido de $30 \mathrm{a}$ $50 \%$ (observação empírica).

Estágio 2 - Convertendo preparações internas em externas - Este estágio envolve duas noções básicas muito importantes:

- reexaminar teoricamente as operações, no sentido de verificar se alguns passos assumidos inicialmente de forma errônea como inerentemente internos, não podem ser transformados em externos;

- encontrar soluções tecnológicas que permitam transformar alguns passos da prepara-

\footnotetext{
(3) As questões expostas a seguir encontram-se no capítulo 3 do livro "A Revolution in Manufacturing: The SMED System" (Shingo, 1983). Cabe ressaltar ainda, que algumas técnicas de operacionalização da metodologia que será exposta nesta seção estão descritas no capítulo 4 do mesmo livro.
} 
ção, que são internos, em externos; por exemplo, pode-se tomar o caso de peças que usualmente têm seu pré-aquecimento feito apenas depois que ocorre a parada da máquina; isto pode ser convertido, em muitos casos, fazendo o pré-aquecimento das peças realizar-se previamente, enquanto as máquinas ainda estão funcionando.

Estágio 3 - Simplificar todos os passos das preparações internas - Neste estágio busca-se analisar detalhadamente cada passo da operação de preparação, visando a redução dos tempos da mesma. Os estágios 2 e 3 não são, necessariamente, executados de forma sequencial, podendo ser realizados de forma simultânea. $O$ autor separou estes estágios visando destacar que tratam-se de duas noções conceitualmente distintas: o estágio 2 envolve uma análise, enquanto o estágio 3 envolve um conjunto de soluções tecnológicas.

Entretanto, embora a logicidade da abordagem de Shingo para o ataque à problemática da troca rápida de ferramentas traga resultados positivos para o fluxo de produção da empresa, o modelo falha ao não apresentar um procedimento de priorização ao tratamento do problema. Em outras palavras, uma vez que a análise simultânea de todos os recursos produtivos é impossivel e que o impacto, em termos globais para a empresa, da redução de set-up é diferenciado para cada recurso, fazse necessário um procedimento auxiliar que "guie" os esforços para a minimização deste problema.

Assim, a partir deste momento apresentarse-á a TOC como base para a sistemática de priorização da abordagem de troca rápida de ferramentas.

\section{A Utilização da Teoria das Restrições (TOC) como Ferramenta de Priorização na Redução de SET-UPs}

A TOC é uma teoria criada por Eli Goldratt, (1990) e tem em seu cerne a visualização da empresa como uma corrente, formada por elos interdependentes, sendo que inevitavelmente a mesma apresentará elos mais fracos, os quais limitarão o rendimento do processo. Estes elos fracos são chamados de restrições e, em termos de empresa, determinam a capacidade de geração de riqueza de empresa. Assim sendo, o conceito de restrição é amplo e envolve as variáveis mercadológicas, passando pelas produtivas e chegando às politicas gerenciais da empresa.

Sabendo da importância do bom gerenciamento das restrições, Goldratt prescreveu 5 etapas, as quais compõem a Teoria das Restrições:

1. identificar o sistema de restrições - antes do ataque a um problema, deve-se preliminarmente identificá-lo;

2. decidir a forma mais eficiente de utilizar-se o sistema de restrições - para obter-se a melhor resposta do conjunto de restrições é necessário utilizá-las visando exclusivamente a meta da empresa, isto é, procurando gerar o maior ganho possível;

3. ajustar os demais recursos do sistema às decisões tomadas no passo anterior - este 
passo propõe a sincronização do sistema; enquanto a regra dois estabelece uma cadência de operação, este passo assegura o cumprimento do ritmo definido;

4. elevar o sistema de restrições - uma vez que os passos anteriores definem o ganho máximo da empresa, a única maneira de incrementá-lo seria através da elevação da capacidade da restrição;

5. caso o sistema de restrições seja quebrado, inicializar o processo novamente desde a primeira etapa - um sistema de restrições deve ser dinamicamente avaliado, pois uma vez alterado, cria-se um novo sistema, onde eventualmente surgirá uma outra restrição principal.

Embora estes passos tenham sido, em um primeiro momento, utilizados como base do processo de sequenciamento da produção por parte da TOC, o mesmo pode ser extrapolado para a empresa como um todo, servindo como um priorizador de ações a serem tomadas.

No caso específico da redução de set-ups, através do método de TRF, o modelo serviria como um balizador, mostrando pontos específicos dentro do processo produtivo a serem atacados, os quais gerariam impactos maiores para a empresa. O que poderá ser visualizado, de forma didática, no exemplo prático apresentado na seqüência do trabalho.

\section{Exemplo Prático}

Visando a discussão dos conceitos descritos anteriormente, utilizar-se-á um exemplo simplificado, o qual mostrará a operacionalização da abordagem recomendada, incorporada na atividade de planejamento da produção. $O$ exemplo contará com uma pequena empresa que fabrica 4 produtos finais, manufaturados em 4 recursos produtivos, os quais possuem uma capacidade de 40 horas por semana. Os dados de roteiro de produção e quantidades semanais de produção são apresentados na Tabela 1 .

Dados estas condições, a atividade de planejamento da produção, baseando-se na TOC, seguiria os seguintes passos:

\section{1 - Identificação da restrição do sistema:} para tanto utilizar-se-á a noção de cargamáquina, buscando identificar um eventual recurso com uma demanda superior à sua capacidade ( 40 horas/semana).

Recurso A: $(7+3)+(6+4)+(6+3)+(8+4)=41$

Recurso B: $(3+6)+(5+4)+(4+12)+(3+10)=47$

Recurso $\mathrm{C}:(2+7)+(3+2)+(3+9)+(1+2)=29$

Recurso D: $(3+4)+(3+4)+(4+3)+(6+4)=29$

Para o presente exercício fica claro que o recurso $B$ é a restrição do sistema; dessa maneira, dever-se-ia passar para a segunda etapa do método.

2 - Explorar a restrição do sistema: explorar ao máximo uma restrição significa gerar o máximo de dinheiro possível da mesma. Neste caso específico, seria necessário o pleno atendimento do mercado, que teria como conseqüência, a curto prazo, a necessidade do aumento de capacidade do recurso $B$, através do uso de horas-extras, por exemplo.

\section{Horas-extras - Recurso B $=7$ horas}

Uma vez tendo explorado a restrição, será necessário o ajuste dos demais recursos produtivos da empresa. 


\begin{tabular}{c|c|c|c|c|c|c|c|c|c}
\hline \multirow{2}{*}{ PROdUTO } & \multicolumn{2}{|c|}{ A } & \multicolumn{2}{c|}{ B } & \multicolumn{2}{c|}{ C } & \multicolumn{2}{c|}{ D } & $\begin{array}{c}\text { PRODUÇÃo } \\
\text { (peças/ } \\
\text { semana) }\end{array}$ \\
\cline { 2 - 9 } & PREP & PROC & PREP & PROC & PREP & PROC & PREP & PROC & 10 \\
\hline 1 & 7 & 0.3 & 3 & 0.6 & 2 & 0.7 & 3 & 0.4 & 20 \\
2 & 6 & 0.2 & 5 & 0.2 & 3 & 0.1 & 3 & 0.2 & 30 \\
3 & 6 & 0.1 & 4 & 0.4 & 3 & 0.3 & 4 & 0.1 & 20 \\
\hline
\end{tabular}

Tabela 1 - Roteiro de produção (preparação em horas e tempo de processamento em horas/peça)

3 - Subordinação dos demais recursos dos sistemas: nesta etapa identificar-se-á uma outra restrição no sistema - recurso $\mathrm{A}$ - pois o mesmo não apresenta uma capacidade compatível com a decisão tomada no passo anterior. Desta maneira, faz-se obrigatório, a curto prazo, o aumento da capacidade deste recurso.

Horas-extras - Recurso $\mathrm{A}=1$ hora

Desta forma, obter-se-ia um plano de produção semanal factivel para o exemplo apresentado. Entretanto, em termos de médio e longo prazo, a restrição do sistema deveria ser quebrada, evitando o custo de horas-extras e possiblitando um ganho nominal de capacidade. Logo, buscar-se-ia a elevação do sistema de restrições.

4 - Elevar o sistema de restrições: elevar o sistema de restrições significa aumento da capacidade total de geração de riquezas de um recurso. Isto poderia ser alcançado de uma maneira direta através da aquisição de um novo recurso, tendo como contra-partida o custo do investimento. Entretanto, existem soluções de médio/longo prazo, as quais elevam o sistema de restrições a custos menores. Segundo Goldratt (1984), tempo total de uso de um recurso pode ser dividido em ativação e utilização. A ativação de um recurso seria a parcela de tempo de uso do mesmo sem a geração de riqueza(e.g. preparaçãoda máquina). Já a utilização, é o tempo gasto por este recurso em atividades que geram ganhos. Portanto, a elevação do sistema poderia ser alcançada pela simples transformação da parcela de tempo de ativação emutilização,operacionalizadapela troca rápida de ferramentas, ou seja, pela redução dos tempos de set-ups.

Para tanto, seguir-se-á os passos recomendados por Shingo e descritos na seção 4, especificamente para recurso $\mathrm{B}$.

Estágio 1 - Separação da preparação interna da preparação externa: através da série de mecanismos e técnicas propostas por Shingo, buscar-se-ia a identificação destes dois tipos de operações, visando a redução do tempo total de preparação pelo simples paralelismo das atividades.

\begin{tabular}{c|c|c}
\hline \multirow{2}{*}{ PRODUTO } & \multicolumn{2}{|c}{$\begin{array}{c}\text { PREPRAÇĀO } \\
\text { RECURSO B }\end{array}$} \\
\cline { 2 - 3 } & INTERNA & EXTERNA \\
\hline 1 & 2 & 1 \\
2 & 3 & 2 \\
3 & 3 & 1 \\
4 & 2 & 1 \\
\hline
\end{tabular}

Tabela 2 - Tempos de preparação interna e externa após estágio 1

Este simples procedimento teria como resultado um incremento de 5 horas para a 
utilização do recurso $\mathrm{B}$, mais ainda não seria o suficiente para a eliminação do uso de horasextras. Logo, faz-se necessário a aplicação do segundo estágio de método do Shingo.

\section{Estágio 2 - Conversão da preparação} interna em externa: este estágio extrapola a parte organizacional do estágio anterior e desce ao nivel técnico do recurso/equipamento, buscando alternativas que visem a transformação das operações internas em externas.

\begin{tabular}{c|c|c}
\hline \multirow{2}{*}{ PRODUTO } & \multicolumn{2}{|c}{$\begin{array}{c}\text { PREPRAÇÃO } \\
\text { RECURSO B }\end{array}$} \\
\cline { 2 - 3 } & INTERNA & EXTERNA \\
\hline 1 & 1.5 & 1.5 \\
2 & 2.5 & 2.5 \\
3 & 2 & 2 \\
4 & 2 & 1 \\
\hline
\end{tabular}

Tabela 3 - Tempos de preparação interna e externa após estágio 2

Desta maneira incrementa-se a utilização da máquina em duas horas, quebrando, desta forma, o gargalo-recurso $B$.

Neste ponto, faz-se necessária uma discussão teórica sobre o próximo passo, pois o caminho natural a ser seguido seria, uma vez a restrição do sistema ter sido quebrada, reinicializar o processo novamente, na busca da nova restrição(Regra 5 da TOC). Entretanto, sabe-se que, com um pouco mais de esforço poder-seia reduzir ainda mais os tempos de preparação interna, uma vez que todo o esforço técnico tenha sido inicializado. Assim sendo, levantase, neste ponto, uma questão de custo-beneficio ("trade-off"): valeria a pena a continuação do trabalho de redução de set-up neste recurso, mesmo em não se tratando de um gargalo?

Certamente esta resposta deverá ser dada caso a caso, mas faz-se necessário o estudo mais detalhado desta questão sobre o ponto de vista prático. Algumas questões devem ser analisadas:

- a possibilidade ou não do recurso tratado voltar a ser um eventual gargalo, quando da utilização dométodo de troca rápida de ferramentas em outros pontos do processo produtivo;

- a disponibilidade ou não de outros grupos de trabalho, que podem executar trabalhos paralelos nos novos gargalos produtivos;

- a capacidade ou não de conseguir reduzir substancialmente (idealmente, menos de 10 minutos) os tempos de preparação no recurso tratado em pouco tempo.

Observa-se a necessidade do aprofundamento teórico desta discussão, incluindo como base empírica de análise casos reais de empresas nos diversos ramos industriais. Ainda será preciso investigar a relação da troca rápida de ferramentas com outros fatores, tais como: diminuição dos refugos e retrabalhos devido à minimização de ajustes e regulagens, etc.

\section{Conclusões}

São as seguintes as conclusões deste trabalho:

- o uso adequado do método de troca rápida de ferramentas é um dos meios essenciais para que seja possível atingir o fim proposto: 
produzir em ambientes flexíveis do tipo justin-time;

- os modelos propostos para a troca rápida de ferramentas, como o de Shingo, são insuficientes para abordar de forma organizada e priorizada a questão da capacidade; isto ocorre porque estes modelos não possuem nenhum mecanismo interno de priorização do tratamento do problema; de forma mais clara, as metodologias existentes de troca rápida de ferramentas não indicam em que postos de trabalho devem ser feitos os primeiros esforços e, posteriormente, não indicam como realocar logicamente os esforços dos grupos de trabalho de TRF;

- dentro da lógica da sinergia entre técnicas e princípios de produção, a TOC, se convenientemente acoplada à metodologia de TRF, é capaz de indicar soluções racionais ao problema da priorização. A dinamicidade da lógica da TOC permite uma abordagem conveniente à questão, impedindo que uma visão estática torne os esforços, no sentido da TRF, pouco efetivos para $o$ atingimento da meta global da empresa (geração de ganhos através de vendas).

- para efeito de evitar a má localização dos esforços no sentido da TRF, o exemplo mostra que não há lógica em atacar-se os postos de trabalho que tenham um tempo absoluto maior de preparação; isto porque, na maioria dos casos, estes postos não constituem-se nas principais restrições do sistema;

- confrontando os estágios da metodologia de Shingo e os passos da TOC, certos caminhos lógicos podem ser estudados. Embora uma abordagem ortodoxa, analisando a redução do set-up, possa levar a uma situação de elevação de restrição do sistema (regra 4), uma análise deve ser feita para a verificação de um novo sistema de restrições (regra 5). Isto pode impedir a continuidade do trabalho do grupo no sentido de baixar o tempo de preparação do recurso original. Entretanto, uma vez inicializados os esforços em uma máquina, talvez seja coerente finalizar o trabalho na mesma. Esta discussão aponta, a princípio, duas correntes de investigação necessárias:

1 - haveria um trade-off, caso a caso, entre o uso ortodoxo da TOC e a continuidade empírica dos esforços em uma máquina gargalo, ou é possivel chegar-se a uma abordagem metodológica coerente e geral para a questão?

2 - no caso de ser possível uma abordagem geral para esta questão, ela estaria em separar as ações organizacionais (passo 1 da metodologia de Shingo) das ações tecnológicas, (passo 2 e 3 ) e inserir a TOC dentro desta classificação?

\section{Referências Bibliográficas}

ANTUNES, Júnior J. A. V.. - Considerações sobre a concorrência intercapitalista, a filosofia Justo-a-Tempo e o controle sobre os trabalhadores. Análises, Porto Alegre, volume 1, número 3, 1990, p. $257-275$

CORIAT, B.. - Automação programável: novas formas e conceitos de produção. In: SCHIMITZ, H. \& CARVALHO, R. Q.: Automação, Competitividade e Trabalho: a experiência internacional, São Paulo, 1988. 
DIAS, Marco A.. - Administração de Materiais: uma abordagem logística. Editora Atlas, São Paulo, 1986.

GOLDRATT, Eliyhau M. \& COX, Jeff - A mcta. Editora do IMAM, São Paulo, 1986.

GOLDRATT, Eliyhau M. - What is this thing called theory of constrainsts and how shold it be implemented? Nort River Press, New York, 1990.

HARMON, Doy \& PETERSON, Leroy D.. Reinventando a fábrica II - Conceitos modernos de produtividade aplicados na prática. Editora Campus Ltda, Rio de Janeiro, 1991.
SAYER, Andrew. New developments in manufacturing: the Just-in-Time system. In: Capital 8 Class, 1986.

SHINGO, Shingeo - Study of Toyota productions system from industrial engineering Veiwpoint. Japan Management Association, Shiba-part Mimatoku, Tokyo, Japan, 1981.

SHINGO, Shingeo - A revolution in manufacturing: the SMED System. Productivity Press, Cambridge, 1983.

STALK, George Jr. - Time - the next source of competitive advantage. In: Harvard Business Review, July-August, 1988. 